\title{
Seasonal Variation of Turbidity in Lake Biwa*
}

\author{
Shuichi ENDOH ${ }^{1}$, Kunihiko SAGI ${ }^{1}$, Naonori FUKUYAMA ${ }^{1}$, \\ Munetsugu KAWASHIMA ${ }^{1}$ and Yasuaki OKUMURA ${ }^{2}$ \\ ${ }^{I}$ Faculty of Education, Shiga University, 2-5-1 Hiratsu, Otsu 520-0862, Japan; \\ Faculty of Engineering, Osaka Electro-Communication University, \\ 1130-70 Kiyotaki, Shijonawate, Osaka 575-0063, Japan
}

\begin{abstract}
Seasonal variation of the turbidity (suspended substance) has been investigated in Lake Biwa. During the last five years, vertical and horizontal distributions of water temperature, turbidity, electric conductivity and chlorophyll-a have been obtained both in the south basin and the southern part of the north basin of Lake Biwa. The benthic nepheloid layer (BNL) developed in the seasons of thermal stratification, and is not detectable in the non-stratification period (winter). The BNL is mainly maintained by the organic matter such as phytoplankton under decomposition. However, the turbidity in the nepheloid layer was much affected by the turbid water from rivers after heavy rain fall. In this case, the major component of the suspended substance (SS) in the nepheloid layer was inorganic soil. The particulate P concentration, which is originated from phytoplankton, also increased after a rain fall. This suggests that phytoplankton in the surface layer sinks with clay and silt coming through rivers. From summer to the end of the stratification period, another kind of turbidity appeared in the bottom layer. This is caused by the chemical reaction of manganese under the anoxic condition. The resuspension of bottom sediment by strong currents also occurred, but it is not a major process for maintaining the $B N L$.
\end{abstract}

Keywords: Lake Biwa, turbidity, river water, nepheloid layer

\section{Introduction}

The benthic nepheloid layer (BNL) in Lake Biwa has been studied by Kawai et al. (1985), Ichiki et al. (1985), Tsuda et al. (1989), Kumagai (1987), and Shimoda (1993). Maeda et al. (1987) proposed possible mechanisms for maintaining the BNL, that is, 1) resuspension of the bottom sediment , 2) inflow of river water along the bottom slope, and 3) continuous floating of fine particles just above the bottom. Kawashima and Takamatsu (1995) pointed out another kind of turbidity caused by the chemical reaction of manganese in the bottom layer.

In this article, we introduce the seasonal variation of the turbidity in Lake Biwa, and discuss on the maintenance mechanisms of the BNL.

\footnotetext{
${ }^{*}$ Received 1997-02-25; accepted 1998-03-27.
} 


\section{Observation}

During 1992 and 1993, we carried out the observation of water temperature, turbidity, electric conductivity and chlorophyll-a both in the south basin and the north basin of Lake Biwa almost every 10 days. The TCT profiler was used for measuring the vertical profiles of water quality. At every station, transparency and wind were also measured. The positioning of the stations were made by GPS. In 1995 and 1996, similar observations have been made once a month in the southern part of the north basin. Figure 1 shows the arrangement of the observation stations. Automatic current meters and turbidity meters have been set in these area to obtain the continuous records of current, turbidity and water temperature.

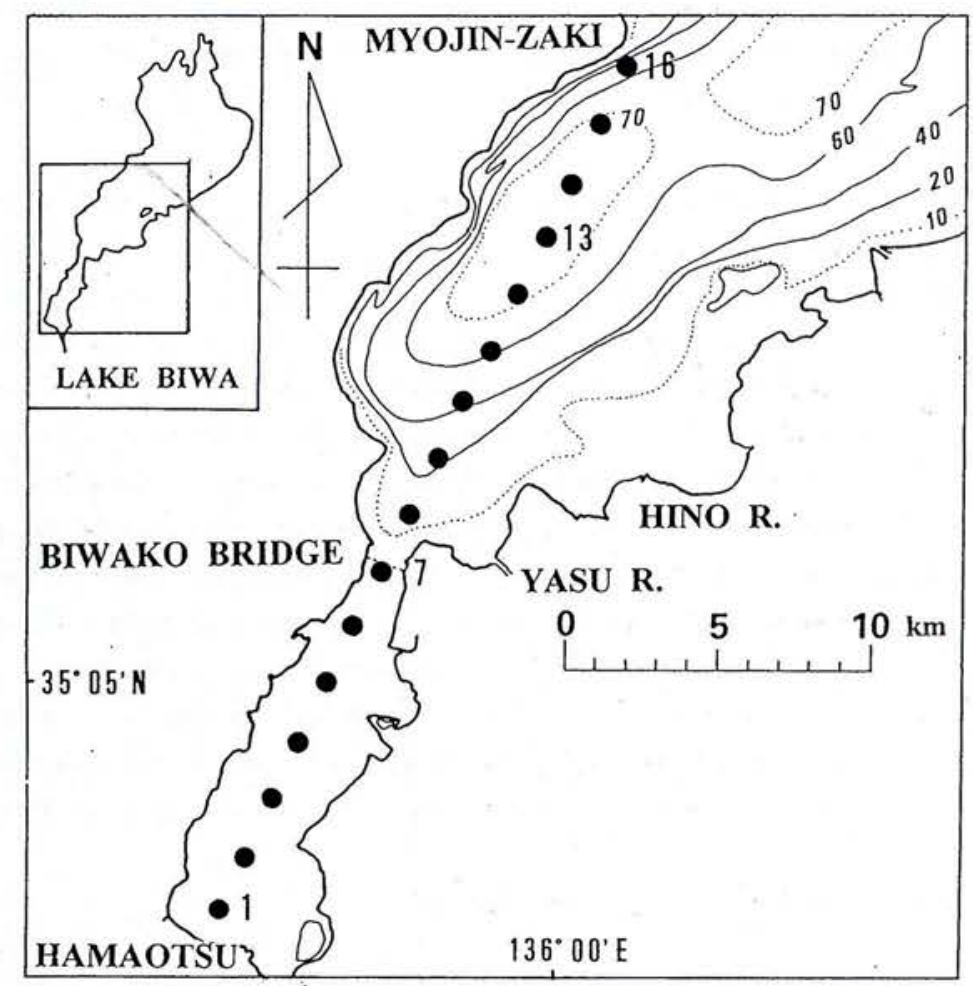

Fig. 1 Locations of observation stations in Lake Biwa in 1992 and 1996

Water sampling have also been made at three depth (surface, middle, and bottom) at Sta. 13 (Fig. 1) every 10 days in 1992 and 1993. By filtering the sampled water, we analyzed the concentration of suspended substance (SS), ignition loss and concentrations of nine elements of $\mathrm{Al}, \mathrm{Si}, \mathrm{Ti}, \mathrm{Fe}, \mathrm{Ca}, \mathrm{K}, \mathrm{P}, \mathrm{S}$ and $\mathrm{Mn}$ by X-ray fluorescence spectrometry.

\section{Result}

Fig. 2 shows the seasonal variations of water temperature and turbidity at Sta. 13. In summer, 
the strong thermal stratification can be seen, but water temperature is almost uniform in winter. A large amplitude of temperature change in this figure is considered to be caused by strong wind and internal waves.
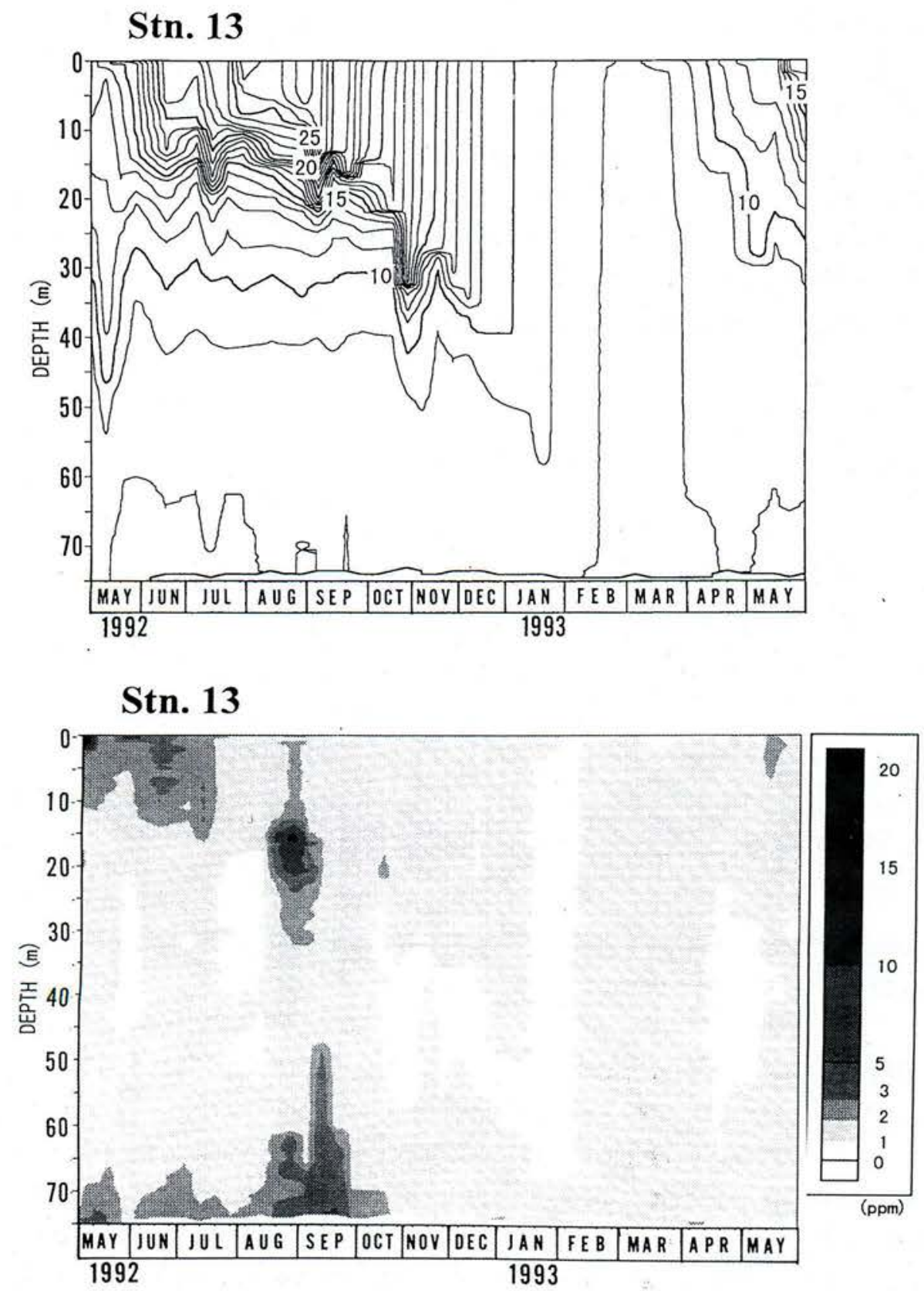

Fig. 2 Seasonal changes of water temperature and turbidity at Station 13 from May 1992 to May 1993 
Supplement

High turbidity was often observed at this station throughout a year. In the spring season, the surface water is much turbid by the bloom of the phytoplankton. In summer, very turbid water exists in the thermocline depth. This turbidity was originated from the river water after a heavy rain fall. In the bottom.layer, a relatively high turbidity was observed in the stratification period and the benthic nepheloid layer is maintained throughout this season. In the winter season, the turbidity is less through the water column by the vertical mixing and convection.

Fig. 3 shows the seasonal variations of SS concentration and the ignition loss in the bottom water at Sta. 13. Daily precipitation around Lake Biwa is also shown in this figure. The concentration of SS largely fluctuated in the stratification period. After heavy rain fall, the SS increased rapidly, but decreased soon. The inverse relationship can be found between the SS concentration and the ignition loss in this case. This means the rapid increase of SS was mainly caused by the inorganic matter (soil) through the river.

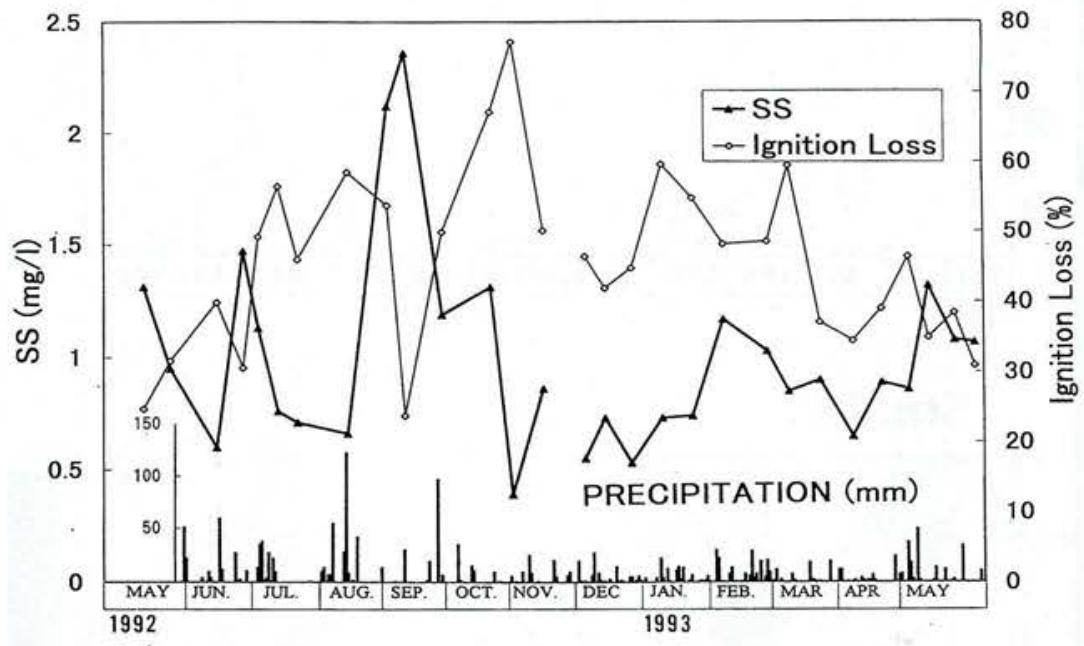

Fig. 3 Seasonal changes in SS concentration and ignition loss of SS in the bottom layer of Station 13 from May 1992 to May 1993.

Fig. 4 shows the seasonal variations of three elements of $\mathrm{Al}, \mathrm{Mn}$ and $\mathrm{P}$ in $\mathrm{SS}$ in the bottom layer of Sta. 13 together with that of the SS concentration. The element Al represents the soil originated material, and $\mathrm{P}$ represents the organic matter such as phytoplankton. In the season of thermal stratification, the high correlation is found between the SS concentration and $\mathrm{Al}$ concentration. This means the inorganic matter coming from the river developed the benthic nepheloid layer after a heavy rain fall. The particulate $\mathrm{P}$ concentration in the BNL was also increased at this time. This suggest that phytoplankton in the surface layer sinks with clay and silt entering via the rivers. The soil particles with rather high density sink rapidly and pile up on the bottom sediment. As a result, the turbidity in the benthic layer decreased quickly. 
On the other hand, the concentration of $\mathrm{P}$ did not decrease quickly. This indicates the organic matter as phytoplankton is very difficult to sink to the bottom by its low density. In the autumn and winter, the concentration of $\mathrm{P}$ fluctuated similar to the SS concentration. In these season, the ignition loss is rather high (about $50 \%$ ). This indicates the background turbidity in the BNL is organic matter such as phytoplankton under decomposition.

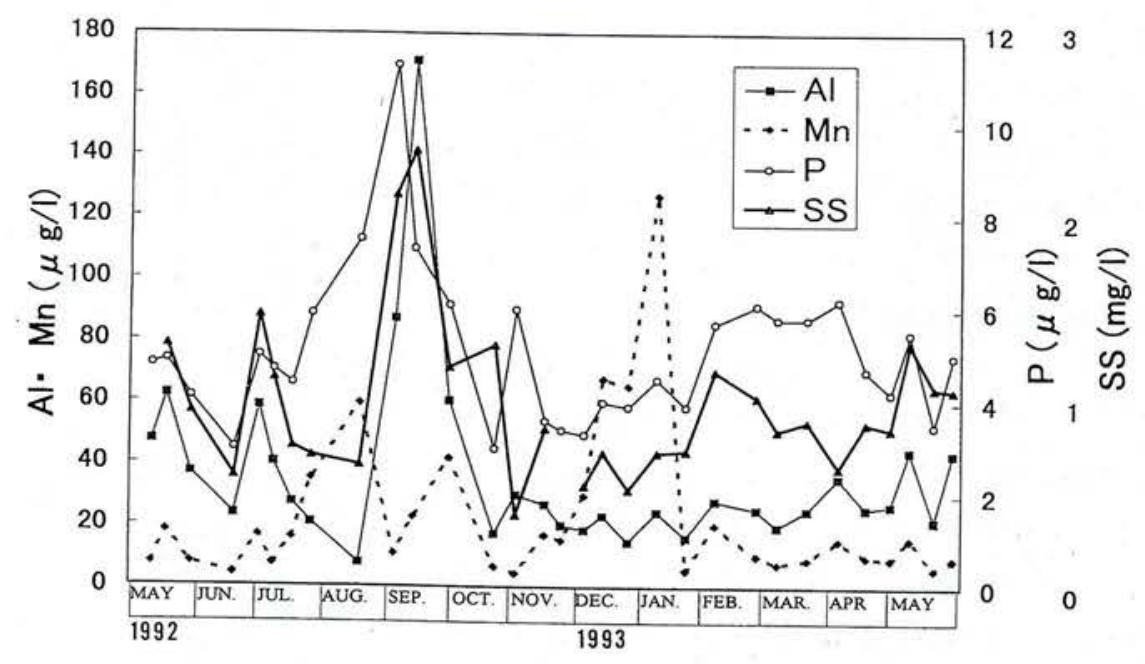

Fig. 4 Seasonal changes in SS concentration and particulate $\mathrm{Al}, \mathrm{Mn}$, and $\mathrm{P}$ in the bottom
layer of Station 13 from May 1992 to May 1993

The concentration of Mn began to increase from the end of summer, and reached its maximum value in the beginning of the winter. This turbidity increasing was caused by the chemical reaction of Mn under anoxic condition in the bottom layer.

Fig. 5 shows the vertical profiles of water temperature, turbidity, electric conductivity and chlorophyll-a at the southern part of the north basin of Lake Biwa. Very turbid water with high conductivity exists at the top of the thermocline. This high turbidity was introduced from the river because of its high conductivity. The chlorophyll- $a$ also has its local peak at this depth. The second maximum of the turbidity is located at the depth of $25 \mathrm{~m}$. This turbidity peak is considered to be the existence of sinking particles intruded from the river after the previous rain fall. The sinking rate is estimated to be $5-10 \mathrm{~m} \cdot \mathrm{day}^{-1}$, and then the particle size is also estimated to be about $8 \mu$ by the Stokes' law assuming the particle density $2.5 \mathrm{~g} \cdot \mathrm{cm}^{-3}$

\section{Discussion}

On the basis of our observation results, we propose some maintenance mechanisms of BNL in Lake Biwa.

The first one is the occasional supply of the turbidity from the rivers. In the season of thermal stratification, the high turbidity was often observed at the thermocline depth $(10-15 \mathrm{~m})$. This 
Supplement

turbid water has low ignition loss and high concentrations of Ti and Al. This means that colder river water containing inorganic soil sinks at the river mouth and then intrudes into the thermocline depth. This intrusion creates the intermediate nepheloid layer. The soil-originated inorganic particles sink rapidly and develop the BNL after a rain fall. It is to be noted that the organic matter sink together with the soil particles. This co-precipitation mechanism is very important to reveal the metabolism in the lake. After the supply of the river water stopped, the turbidity both in the thermocline and bottom layer decrease soon.

The second mechanism is the precipitation and resuspension of organic matter such as phytoplankton. In the stratification period, the primary production is very high in the surface layer. We operated a submerged video camera to observe a lot of lake snow precipitating very slowly not only in the surface layer but also in the thermocline and the bottom layer. These fine and less dense organic matter sinks and reaches to the lake bottom, but is difficult to pile up on the bottom sediment because of the existence of the turbulent flow. Then, the organic matter might continue to drift just above the bottom until it is fully decomposed. This floating material (plankton) should be the background turbidity in the BNL.

The third mechanism may be the resuspension of the bottom sediment. This mechanisms has been considered to be the main process in the past. To clarify this, we made continuous observation of current and turbidity in the bottom layer. The results show the very strong current (more than 30 $\mathrm{cm} \cdot \mathrm{s}^{-1}$ ) can rolled up the bottom sediment and create the high turbidity (Fig.6). However, the turbidity decreased rapidly after this event. This phenomenon was observed only once a month, and it is not a major mechanism for maintaining the BNL.
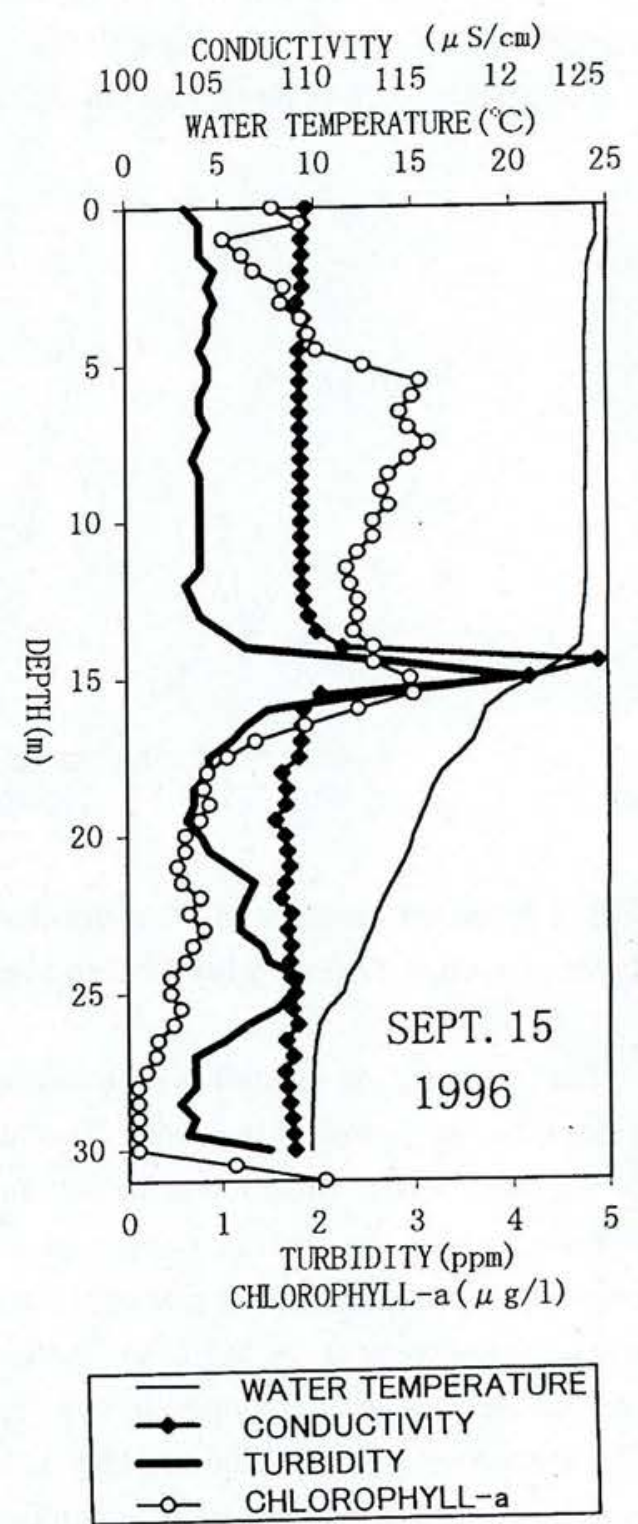

Fig. 5 Vertical distributions of water temperature, turbidity, electric conductivity and chlorophyll $a$ at Station C3 on September 15, 1996 
The fourth is the chemical reaction of manganese under the anoxic condition (Kawashima and Takamatsu, 1995). This kind of turbidity supply was observed especially in late autumn and early winter when the bottom water was getting anoxic by the decomposition of the organic matter.

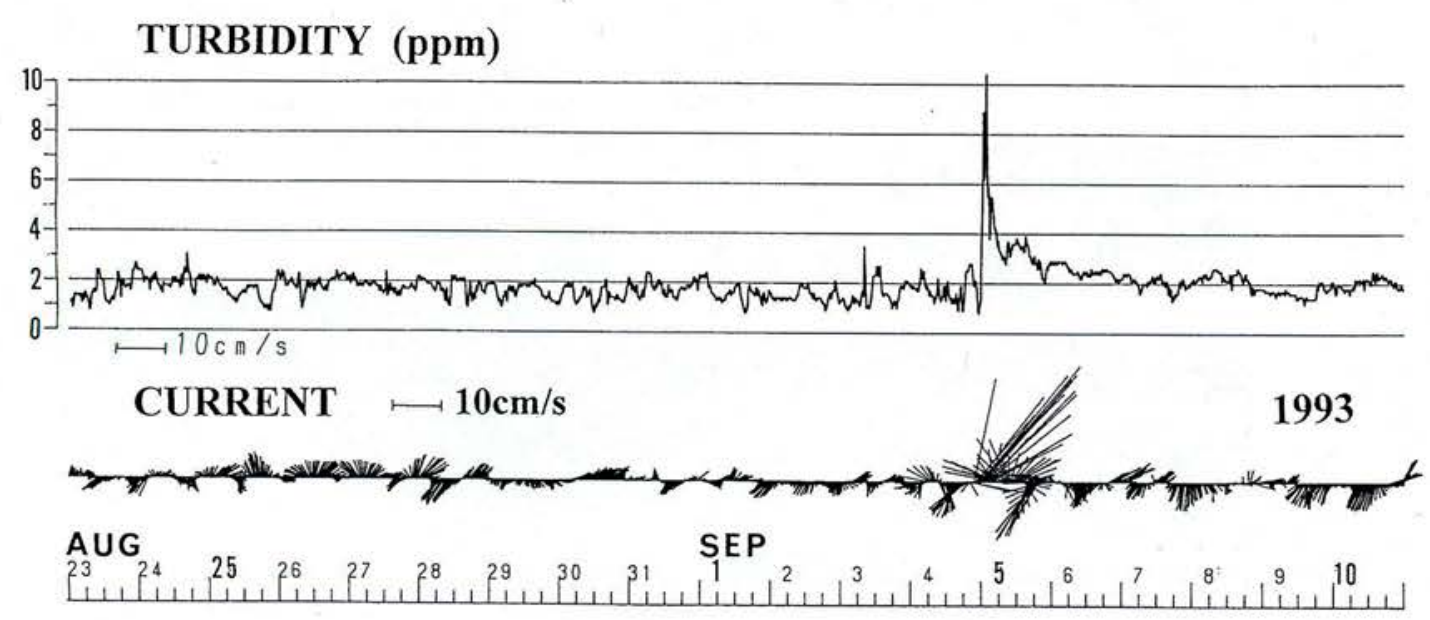

Fig. 6 Time series of turbidity (top) and current vectors (bottom) in the bottom layer near Station 13 from August 23 to September 10, 1993.

\section{Acknowledgments}

We express our sincere thanks to I. Okamoto, professor emeritus of Shiga University, for his suggestion throughout this study. We also thank to many students of Shiga University and Osaka Electro-Communication University for their help in field observations.

\section{References}

Ichiki, S., and Nakamura, T. 1985.Bull. Shiga Pref. Inst. Public Health and Environ. Sci.20.

Kawai, A.1985. Rep. Lake Biwa Res. Inst., K26.

Kawashima, M., and Takamatsu, T. 1995.Ocean Chem. Study.8.

Kumagai, M. 1987. Rep. Lake Biwa Res. Inst., 86A04.

Maeda, H. et al. 1987. Rep. Lake Biwa Res. Inst., 86A05.

Shimoda, C.1993. Master thesis of Kinki University.

Tsuda, R. et al.1989. Technical Rep. 5, Lake Biwa Res. Inst. 